\title{
Projected effects of nonpharmaceutical public health interventions to prevent resurgence of SARS-CoV-2 transmission in Canada
}

\author{
Victoria Ng PhD, Aamir Fazil MEng, Lisa A. Waddell MSc PhD, Christina Bancej MSc PhD, Patricia Turgeon DVM PhD, \\ Ainsley Otten BEng, Nicole Atchessi PhD, Nicholas H. Ogden BVSc DPhil
}

Cite as: CMAJ 2020 September 14;192:E1053-64. doi: 10.1503/cmaj.200990; early-released August 10, 2020

See related article at www.cmaj.ca/lookup/doi/10.1503/cmaj.201758

\begin{abstract}
BACKGROUND: Continual efforts to eliminate community transmission of severe acute respiratory syndrome coronavirus 2 (SARS-CoV-2) will be needed to prevent additional waves of infection. We explored the impact of nonpharmaceutical interventions on projected SARS-CoV-2 transmission in Canada.
\end{abstract}

METHODS: We developed an agestructured agent-based model of the Canadian population simulating the impact of current and projected levels of public health interventions on SARSCoV-2 transmission. Interventions included case detection and isolation, contact tracing and quarantine, physical distancing and community closures, evaluated alone and in combination.
RESULTS: Without any interventions, $64.6 \%$ (95\% credible interval [Crl] 63.9\%$65.0 \%$ ) of Canadians will be infected with SARS-CoV-2 (total attack rate) and 3.6\% (95\% Crl 2.4\%-3.8\%) of those infected and symptomatic will die. If case detection and contact tracing continued at baseline levels without maintained physical distancing and reimplementation of restrictive measures, this combination brought the total attack rate to $56.1 \%$ (95\% Crl 0.05\%-57.1\%), but it dropped to $0.4 \%(95 \% \mathrm{Crl} 0.03 \%-23.5 \%)$ with enhanced case detection and contact tracing. Combining the latter scenario with maintained physical distancing reduced the total attack rate to $0.2 \%$ (95\% Crl $0.03 \%-1.7 \%$ ) and was the only scenario that consistently kept hospital and intensive care unit bed use under capacity, prevented nearly all deaths and eliminated the epidemic. Extending school closures had minimal effects but did reduce transmission in schools; however, extending closures of workplaces and mixed-age venues markedly reduced attack rates and usually or always eliminated the epidemic under any scenario.

INTERPRETATION: Controlling SARSCoV-2 transmission will depend on enhancing and maintaining interventions at both the community and individual levels. Without such interventions, a resurgent epidemic will occur, with the risk of overwhelming our health care systems.

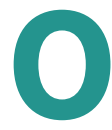

n Mar. 11, 2020, the World Health Organization declared coronavirus disease 2019 (COVID-19), caused by severe acute respiratory syndrome coronavirus 2 (SARS-CoV-2), a pandemic. ${ }^{1,2}$ By June 28, the pandemic included more than 10 million confirmed cases and about 500000 deaths across 188 countries and territories. ${ }^{3}$ Those who acquire SARS-CoV-2 may be asymptomatic or may experience disease manifestations ranging from mild to severe. ${ }^{4}$ Hospital admissions and deaths occur more commonly among older and immunocompromised individuals., 6 Evidence suggests that asymptomatic individuals can transmit the virus ${ }^{7}$ and that symptomatic individuals are infectious before developing symptoms. ${ }^{8-10}$ These characteristics of SARS-CoV-2, unlike previously known coronaviruses in humans, have posed substantial challenges to controlling local and global spread.

Canada's initial public health response emphasized screening of incoming travellers to contain imported cases, with the first case of COVID-19 reported on Jan. 25 in a returned traveller. ${ }^{11}$ Early cases detected in February were linked to returning travellers and their close contacts. ${ }^{12}$ Locally acquired infections were soon noted with cases rapidly increasing in March and 
overtaking travel-related cases by Mar. $15 .{ }^{12}$ Consequently, Canada's public health response shifted from containment to mitigation. Nonpharmaceutical interventions have been employed, such as detection and isolation of infected individuals, tracing of contacts to quarantine exposed individuals, physical distancing measures including community closures, restrictions on travel and large gatherings, and other measures aimed at reducing contacts among individuals. All provinces and territories implemented strict physical distancing measures in mid-March. These efforts have succeeded in controlling the epidemic to date. ${ }^{13}$ However, it is anticipated that without continued efforts to eliminate community transmission, subsequent waves of infections will occur. Given that the interventions used to control COVID-19 are unprecedented and their effectiveness remains unknown, modelling their likely effects across a range of scenarios can guide decision-making. ${ }^{14-16}$

Transmission dynamics of infectious diseases are typically modelled using compartmental models at the population level. ${ }^{17,18}$ In contrast, agent-based models are computer simulations composed of agents that can represent people, places and objects. These models are stochastic, and agents are programmed to interact with other agents within the model environment. Agent-based models allow agents to have unique characteristics and heterogeneity, which makes them suitable for simulating events that occur by chance, for example, whether infection propagates in the early stages of emergence or whether elimination occurs in the final stages. Agent-based models are particularly suited for studying the effectiveness of interventions as these are highly dependent on community structure and population dynamics. ${ }^{19,20}$ We present an agentbased model developed at the Public Health Agency of Canada to estimate projections of SARS-CoV-2 transmission with varying interventions in Canada.

\section{Methods}

Technical details of the model, including parameters derived from published studies and Canadian data, are presented in Appendix 1 (available at www.cmaj.ca/lookup/suppl/doi:10.1503/ cmaj.200990/-/DC1). Our model was developed in AnyLogic 8 Professional 8.5.2 (The AnyLogic Company). As there are multiple outbreaks currently occurring across Canada, our model is a generalized estimate of the situation and does not account for the geographic dispersion of cases seen across jurisdictions.

\section{Interventions and model scenarios}

The model explored 4 interventions (case detection and isolation, contact tracing and quarantine, personal physical distancing to reduce the daily contact rate, and community closure) individually and together (Table 1). The efficacy of each intervention was compared against a "no intervention" scenario, in which no interventions were applied to explore the unchecked progression of COVID-19 in a naïve population. We modelled interventions separately to explore their individual impact, and we estimated the current levels of interventions in Canada to generate a baseline representing the Canadian situation from Feb. 7 to May 10, 2020, when restrictive community closures began being lifted. During the baseline period, we estimate about $20 \%$ of symptomatic cases were identified via case testing and isolated for their remaining infectious period; ${ }^{21} 50 \%$ of household members of identified cases also isolated (estimate); $50 \%$ of exposed cases were identified via contact tracing and quarantined before being infectious (estimate); $100 \%$ of schools, $40 \%$ of workplaces and $50 \%$ of mixed-age meeting venues were closed from Mar. 16 to May 10;22,23 and there was a further $20 \%$ reduction in contact rate from physical distancing outside of home. ${ }^{24,25}$ The baseline was validated against locally acquired cases in Canada (Appendix 1, Figure S2).

\section{Table 1: Nonpharmaceutical interventions explored in the model}

\section{Intervention}

type

Case detection and isolation

Contact tracing and quarantine

Physical distancing

Community closure

\section{Impact of intervention}

Model component

Mild symptoms thereby reducing community transmission. Agents that are identified via case testing are isolated at home for 14 days. In addition, a proportion of household members also isolate unless they have been previously infected and are immune.

Note that by the time agents arrive in the mildly symptomatic state, they have already been infectious for 1 to 3 days, but isolating them in this state will prevent a further 3 to 7 days of potential community transmission. Isolated agents can continue to infect household members, but at a reduced contact rate of $50 \%$ as we assume sick individuals will impose some form of physical distancing in the household.

Contact tracing to identify individuals who have been exposed and infected but are not yet infectious. This Exposed intervention is one of the most effective because an agent who is quarantined for 14 days in the exposed state will not be a source of community infection at any point during their infection.

Reduce the number of contacts per day; can be applied to the entire population or targeted by age group. Physical distancing was applied only outside of the household.

All agent states

Closure of schools, workplaces and mixed-age venues either as a proportion (e.g., 100\% of schools) or as a threshold (e.g., workplaces with 50 or more assigned agents). Agents who are assigned to a community environment that is closed are forced to stay at home until closure has ended. 
Building on the baseline, we modelled 4 scenarios from May 11, 2020, to Jan. 7, 2022, to explore potential trajectories of SARS-CoV-2 transmission in Canada under varying levels of control put in place to compensate for lifting of community closures (Figure 1). Scenarios represented minimal control (case detection

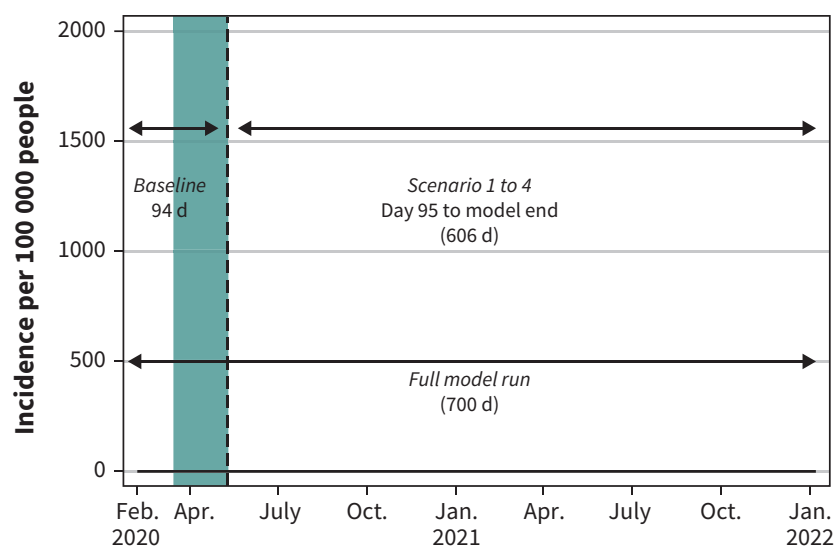

Timeline for baseline period and for the 4 scenarios

Figure 1: The baseline is applied to all 4 scenarios in the first 94 days of model runs. On day 95 (May 11, 2020), a different combination of public health interventions are explored in each scenario. Note: The full model run is 700 days from Feb. 7, 2020, to Jan. 7, 2022. The green bar represents the 8 weeks of restrictive closures (workplace, schools, mixed-age venues representing public spaces, malls, libraries, etc.) within the baseline period, Mar. 16 to May 10, 2020. and isolation, and contact tracing and quarantine remain at baseline levels and physical distancing is not maintained), maintained physical distancing, enhanced case detection and contact tracing, and combined interventions (maintained physical distancing and enhanced case detection and contact tracing) (Table 2). The 4 scenarios were developed based on realistic Canadian targets according to our current effort. Scenarios were then used to compare and explore the impact of extended school and community closures. We modelled extending closures until September 2020. When extending school closures, we lifted closures on workplaces and mixed-age venues, and vice versa. Since schools are closed over summer, this allowed for comparison on the same time scale.

\section{Model output and statistical analyses}

The model produced daily cumulative and incident counts for each age group for each health state. Outcomes that we evaluated included the total attack rate (the total number of new cases divided by the total population), clinical attack rate, asymptomatic attack rate, hospital admissions, ICU admissions and mortality rate by age group. We also constructed epidemic curves of daily case incidence or prevalence per 100000 people. The stochastic outputs are presented as medians from 50 realizations (simulations) per scenario, and values from the 2.5 th and 97.5th percentiles are presented as the 95\% credible interval $(\mathrm{Crl})$. The transmission parameter was fitted to Canadian data producing a reproduction number $\left(\mathrm{R}_{0}\right.$, the average number of additional people who will become infected from each infected

\begin{tabular}{|c|c|c|c|c|c|}
\hline \multirow[b]{2}{*}{$\begin{array}{l}\text { Intervention } \\
\text { type }\end{array}$} & \multirow[b]{2}{*}{$\begin{array}{l}\text { Canadian baseline } \\
\text { (Feb. } 7 \text { to May 10, } \\
\text { 2020) }\end{array}$} & \multicolumn{4}{|c|}{ Scenarios and varying levels of public health interventions applied (May 11, 2020, to Jan. 7, 2022) } \\
\hline & & $\begin{array}{c}\text { Minimal control } \\
\text { (no change to interventions } \\
\text { once closures are lifted and } \\
\text { physical distancing not } \\
\text { maintained) }\end{array}$ & $\begin{array}{c}\text { Maintained physical } \\
\text { distancing }\end{array}$ & $\begin{array}{l}\text { Enhanced case } \\
\text { detection and } \\
\text { contact tracing }\end{array}$ & $\begin{array}{l}\text { Combined } \\
\text { interventions }\end{array}$ \\
\hline $\begin{array}{l}\text { Case detection } \\
\text { and isolation }\end{array}$ & $\begin{array}{l}20 \% \text { detected and } \\
\text { isolated (50\% } \\
\text { household } \\
\text { co-isolate) }\end{array}$ & $\begin{array}{l}20 \% \text { detected and isolated } \\
\text { (50\% household co-isolate) }\end{array}$ & $\begin{array}{c}20 \% \text { detected and } \\
\text { isolated ( } 50 \% \\
\text { household } \\
\text { co-isolate) }\end{array}$ & $\begin{array}{c}50 \% \text { detected and } \\
\text { isolated }^{*}(50 \% \\
\text { household } \\
\text { co-isolate) }\end{array}$ & $\begin{array}{c}50 \% \text { detected and } \\
\text { isolated }{ }^{\star}(50 \% \\
\text { household co-isolate })\end{array}$ \\
\hline $\begin{array}{l}\text { Contact tracing } \\
\text { and quarantine }\end{array}$ & $\begin{array}{l}50 \% \text { of } 20 \% \text { cases } \\
\text { detected traced } \\
\text { and quarantined }\end{array}$ & $\begin{array}{c}50 \% \text { of } 20 \% \text { cases detected } \\
\text { traced and quarantined }\end{array}$ & $\begin{array}{c}50 \% \text { of } 20 \% \text { cases } \\
\text { detected traced and } \\
\text { quarantined }\end{array}$ & $\begin{array}{c}100 \% \text { of } 50 \% \text { cases } \\
\text { detected traced } \\
\text { and quarantined }{ }^{\star}\end{array}$ & $\begin{array}{c}100 \% \text { of } 50 \% \text { cases } \\
\text { detected traced and } \\
\text { quarantined }^{\star}\end{array}$ \\
\hline $\begin{array}{l}\text { Physical } \\
\text { distancing } \\
\text { (reducing daily } \\
\text { contact rate) }\end{array}$ & $\begin{array}{c}20 \% \text { reduction in } \\
\text { contact rate for } \\
8 \text { weeks (Mar. } 16 \text { to } \\
\text { May } 10,2020 \text { ) }\end{array}$ & NA & $\begin{array}{l}20 \% \text { reduction in } \\
\text { contact rate } \\
\text { maintained }^{\star}\end{array}$ & $\mathrm{N} / \mathrm{A}$ & $\begin{array}{l}20 \% \text { reduction in } \\
\text { contact rate } \\
\text { maintained }^{\star}\end{array}$ \\
\hline $\begin{array}{l}\text { Community } \\
\text { closure }\end{array}$ & $\begin{array}{l}100 \% \text { schools, } 40 \% \\
\text { workplaces, } 50 \% \\
\text { mixed-age venues } \\
\text { closed for } 8 \text { weeks } \\
\text { only (Mar. } 16 \text { to } \\
\text { May } 10,2020 \text { ) }\end{array}$ & NA & NA & NA & NA \\
\hline
\end{tabular}


person) of 2.7; we performed sensitivity analyses to explore the impact of varying $R_{0}$ values between 2.0 and 3.0 for each of the 4 scenarios. Statistical analyses and graphs were created using Stata 16 (StataCorp).

\section{Ethics approval}

No ethics approval for our study was required because all data were from published literature and publicly available aggregated data.

\section{Results}

The population total attack rate for community-acquired transmission with no intervention was 64.6\% (95\% Crl 63.9\%-65.0\%) and the mortality rate of those who were symptomatic was $3.6 \%$ (95\% Crl 2.4\%-3.8\%) (Appendix 1, Figure S3). Interventions were modelled individually to explore their effectiveness independently. The most effective individual intervention was partial community closure (total attack rate $7.6 \%, 95 \% \mathrm{Crl} \mathrm{0.36 \% -13.2 \% ),}$

Table 3: Summary of model outputs for the 4 scenarios studied*

\section{Variable}

Total attack rate, $\%(95 \% \mathrm{Crl})$

Clinical attack rate, $\%(95 \% \mathrm{Crl})$

Asymptomatic attack rate, \% (95\% Crl)

Proportion of asymptomatic cases of total cases, $\%(95 \% \mathrm{Crl})$

Clinical cases that are mild (not admitted to hospital), \% (95\% Crl)

Clinical cases that are admitted to hospital (includes ICU), \% (95\% CrI)

Clinical cases admitted into the ICU, \% (95\% Crl)

Hospital-admitted cases admitted into the ICU, $\%(95 \% \mathrm{Crl})$

Mortality rate of clinical cases, \% (95\% CrI)

Total cases (clinical and asymptomatic) per 100000 , median $(95 \% \mathrm{Crl})$

Total clinical cases per 100000 , median (95\% Crl)

Total asymptomatic cases per 100000 , median (95\% Crl)

Total hospital-admitted cases per 100000 , median $(95 \% \mathrm{Crl})$

Total cases admitted into the ICU per 100000 , median $(95 \% \mathrm{Crl})$

Total deaths per 100000 , median $(95 \% \mathrm{Crl})$

Infections acquired at school, \% (95\% Crl)

infections acquired at work, \% (95\% Crl)

Infections acquired in mixed-age venues,

$\%(95 \% \mathrm{Crl})$

Infections acquired in the household, \% (95\% Crl)

No. of infections acquired at school per 100000 , median $(95 \% \mathrm{Crl})$

No. of infections acquired at work per 100000 , median $(95 \% \mathrm{Crl})$

No. of infections acquired in mixed-age venue per 100000 , median $(95 \% \mathrm{Crl})$

No. of infections acquired at home per 100000 , median $(95 \% \mathrm{Crl})$

\section{Minimal control}

$56.1(0.05-57.1)$

$34.5(0.03-35.1)$

$21.6(0.01-22.1)$

$38.5(26.7-42.5)$

$89.1(4.1-21.2)$

$10.9(4.1-21.2)$

$2.8(0.0-7.9)$

$25.4(0.0-50.0)$

$3.2(0.0-3.5)$

56148 (45-57 068)

$34463(31-35087)$

$21615(12-22101)$

3747 (2-3903)

$950(0-1031)$

$1113(0-1208)$

$9.1(1.7-9.7)$

$14.2(9.1-20.5)$

$25.4(14.3-28.2)$

$51.2(50.8-68.2)$

5134 (1-5336)

7947 (4-8239)

14225 (6-14694)

$28659(24-29137)$
Maintained physical distancing

\section{$41.6(0.04-43.4)$}

$25.4(0.03-26.6)$

$16.2(0.01-16.9)$

$38.8(28.6-40.2)$

$89.5(84.0-94.9)$

$10.5(5.1-16.0)$

$2.7(0.0-5.9)$

$25.4(0.0-50.0)$

$2.9(0.0-4.8)$

41579 (44-43455)

25413 (30-26 626)

$16152(14-16881)$

2661 (3-2824)

$665(0-748)$

$739(0-830)$

$8.9(0.0-9.4)$

$13.7(5.3-19.5)$

$24.0(12.3-27.2)$

53.3 (52.9-64.9)

3759 (0-3920)

$5655(2-6000)$

9941 (6-10503)

$22176(23-23080)$

\section{Enhanced case detection and contact tracing}

$0.36(0.03-23.5)$

$0.23(0.02-14.3)$

$0.13(0.01-9.2)$

38.9 (24.1-40.5)

$89.7(80.0-93.0)$

$10.3(7.0-20.0)$

$2.6(0.0-5.0)$

$25.4(0.0-40.0)$

$1.7(0.0-4.0)$

358 (29-23 408)

$227(22-14301)$

129 (7-9249)

$25(2-1464)$

$7(0-387)$

4 (0-296)

$9.1(0.0-13.3)$

$13.1(5.8-25.8)$

$23.2(11.1-27.8)$

$56.2(53.1-69.2)$

$18(0-2365)$

$58.4(51.6-69.7)$

$11(0-159)$

$43(2-3107)$

$33(3-217)$

$83(2-5511)$

$56(3-371)$

$210(16-12591)$

Combined interventions

$0.25(0.03-1.7)$

$0.16(0.02-1.0)$

$0.09(0.01-0.7)$

$36.9(28.6-42.8)$

$90.0(60.9-93.6)$

$10.0(6.5-39.1)$

$2.7(0.0-6.2)$

$24.1(0.0-57.1)$

$1.4(0.0-5.3)$

247 (28-1679)

157 (20-991)

94 (8-688)

$16(4-105)$

$4(0-28)$

$2(0-13)$

$4.8(0.0-10.8)$

$13.3(5.8-19.4)$

$22.4(13.6-30.3)$
Note: $\mathrm{Crl}=$ credible interval, $\mathrm{ICU}=$ intensive care unit.

*Median values from 50 realizations are presented in the table with 2.5 th percentile and 97.5 th percentile values representing the $95 \% \mathrm{Crl}$. Wide range in the $95 \% \mathrm{Crl}$ indicates

dichotomous outcomes across the model runs (i.e., epidemic v. epidemic elimination). The median values indicate the most likely outcome out of 50 realizations. 
then sustained physical distancing (total attack rate $54.0 \%, 95 \%$ $\mathrm{Crl} 53.0 \%-54.7 \%$ ), 20\% case detection and isolation with $50 \%$ household co-isolation (total attack rate 59.3\%, 95\% Crl 0.04\%$60.0 \%$ ) and $50 \%$ contacts traced and quarantined (total attack rate $62.5 \%, 95 \% \mathrm{Cl} 62.0 \%-63.3 \%$ ) (Appendix 1, Figures S4-S7). The only intervention able to extinguish the epidemic on its own was partial community closure (though we note that it would take 18 months to extinguish the epidemic, which is likely unrealistic for such a restrictive intervention), while all other interventions delayed the epidemic. For comparison, we modelled these baseline-level interventions (excluding partial community closure) together; the total attack rate was $42.3 \%$ (95\% Crl 0.03\%-43.3\%), a 22.3\% reduction in total attack rate versus $17.8 \%$ when applied separately (Appendix 1, Figure S8; additional data available on request from the authors).

The total attack rate under the minimal control scenario was $56.1 \%$ (95\% Crl 0.05\%-57.1\%) (Table 3). The highest total attack rate, driven by high asymptomatic infections ( 50\%), occurred in the 10-19 years age groups, the highest clinical attack rate occurred in the 20-54 years age groups, hospital admission and mortality rates were highest in those 75 years and older, and the ICU admission rate was highest in the 65-84 years age groups (because most of those 85 years and older died before reaching the ICU) (data available on request from the authors). The minimal control scenario, which represents case detection and contact tracing interventions maintained at current levels, was effective in reducing the overall total attack rate, but was not sufficient to cause the epidemic to die out or to control a resurgence of the epidemic when restrictive measures (closures) are lifted (Figure 2).

Under the scenario of minimal control with the additions of maintained physical distancing, the total attack rate was reduced to $41.6 \%$ (95\% Crl $0.04 \%-43.4 \%)$. In contrast, the scenario of enhanced case detection and contact tracing attenuated
A

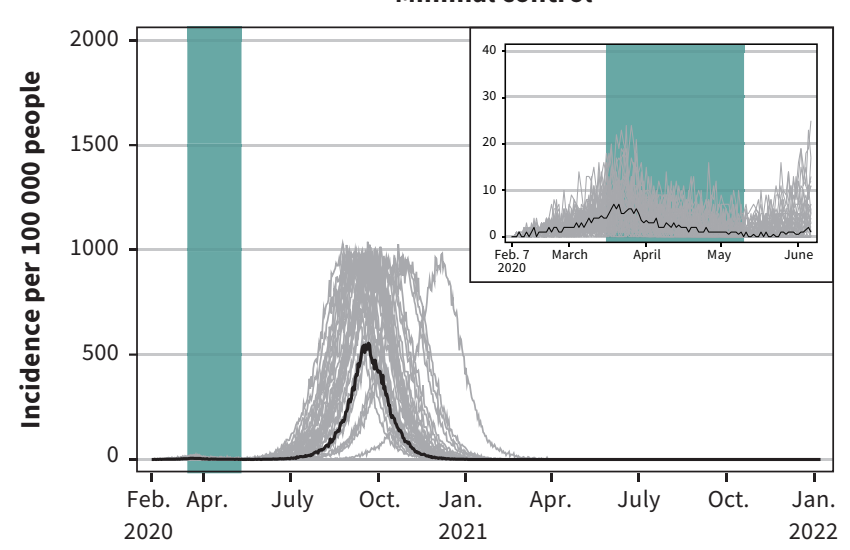

C

Enhanced case detection and contact tracing

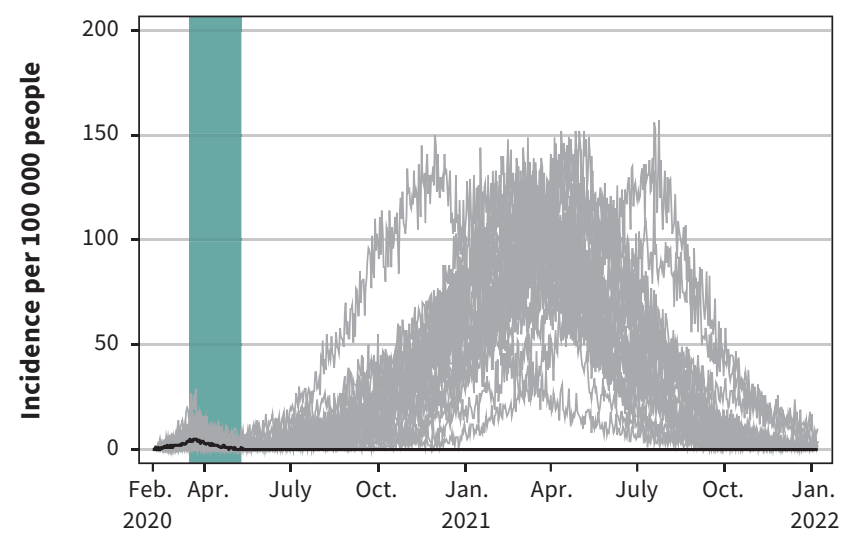

B

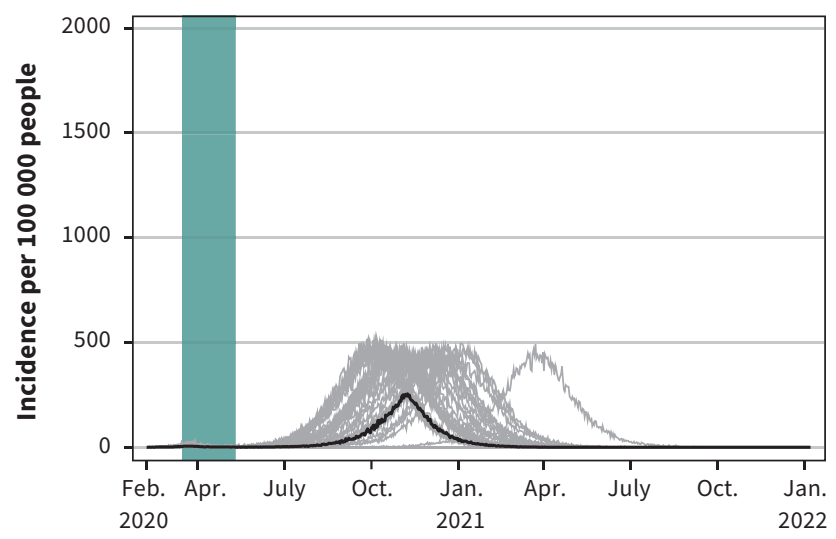

D

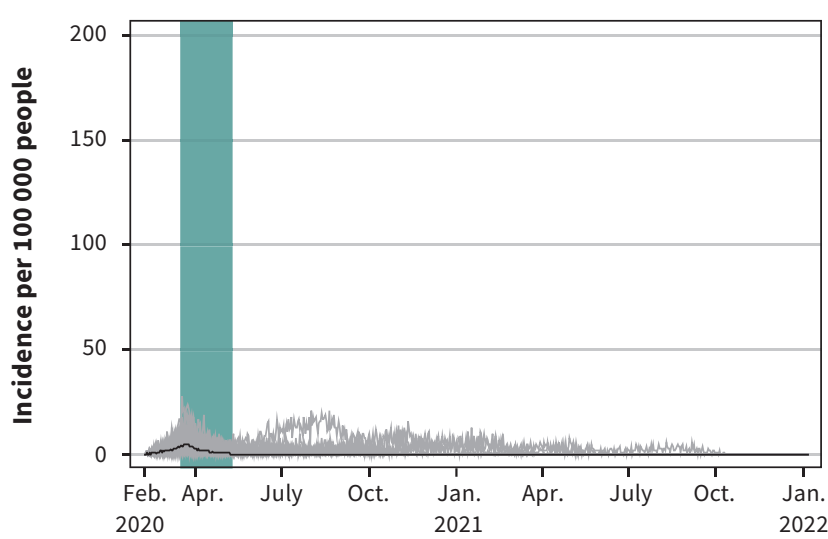

Figure 2: Projected epidemic curves showing daily case incidence per 100000 people for the 4 scenarios, with each scenario progressively applying increasing public health measures after restrictive measures are lifted. Note: The green bar represents the period from Mar. 16 to May 10, 2020, corresponding to restrictive closures. The 4 scenarios show the degree to which withdrawing some of the present interventions, while maintaining or enhancing others, would cause Canada to lose control of the epidemic while community transmission is ongoing. Median values are represented by the black line. Each grey line represents 1 model realization out of 50 per scenario. Note: the $y$-axis scale for the enhanced case detection and contact tracing scenario and the combined interventions scenario is 10 times smaller. 
the total attack rate markedly to $0.4 \%$ (95\% $\mathrm{Crl} 0.03 \%-23.5 \%)$. In the final scenario combining this with maintained physical distancing, the total attack rate was $0.2 \%$ (95\% Crl 0.03\%-1.7\%). However, only in the combined interventions scenario was the epidemic projected to die out completely, although a few realizations indicated that epidemic control may not occur until fall 2021 (Figure 2).

The comparative effects of the 4 scenarios on clinical cases, hospital admissions and ICU admissions paralleled their effects on the total attack rate (Table 3). Total deaths per 100000 were 1113 (95\% Crl 0-1208) with minimal control, 739 (95\% Crl 0-830) with maintained physical distancing, 4 (95\% Crl 0-296) with enhanced case detection and contact tracing and 2 (95\% $\mathrm{Crl}$ 0-13) with combined intervention. In comparison to no interventions, minimal control resulted in 5312 fewer clinical cases, 798 fewer hospital admissions and 320 fewer deaths per 100000 , while combined interventions resulted in 39618 fewer clinical cases, 4529 fewer hospital admissions and 1431 fewer deaths per 100000 (data available on request from the authors). With minimal control or maintained physical distancing, hospital and ICU use would exceed maximum capacity (Figure 3 and Figure 4). With enhanced case detection and contact tracing, hospital and ICU use remained within capacity on average, but exceeded capacity in several model realizations. Only with combined interventions did hospital and ICU use remain consistently within capacity.

Addition of extended school closures to the minimal control or maintained physical distancing scenarios reduced the total attack rate minimally compared with these scenarios alone (Table 4) and simply delayed the epidemic (Figure 5). Compared with minimal control alone, adding school closures resulted in 924 fewer clinical cases, 95 fewer hospital admissions and 26 fewer deaths per 100000 (Table 3, Table 4). Compared with maintained physical distancing alone, adding school closures resulted in 351 fewer clinical cases, 71 fewer hospital admissions and 28 fewer deaths per 100000 . While
A

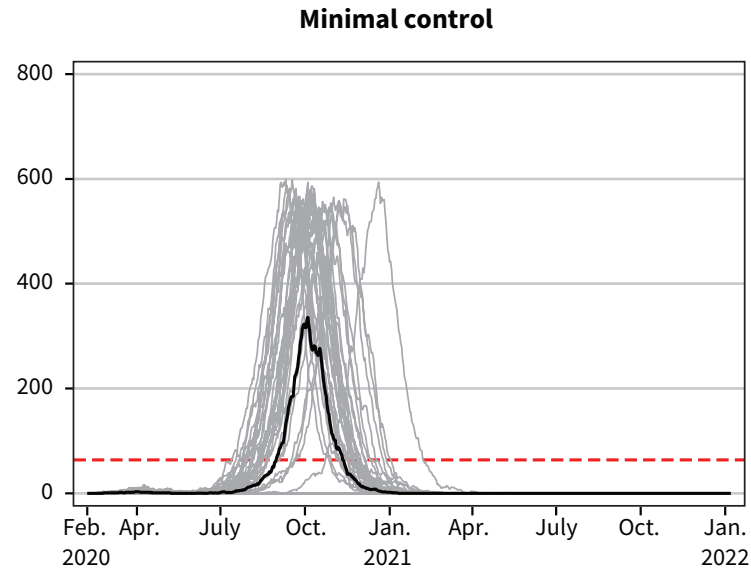

C

Enhanced case detection and contact tracing
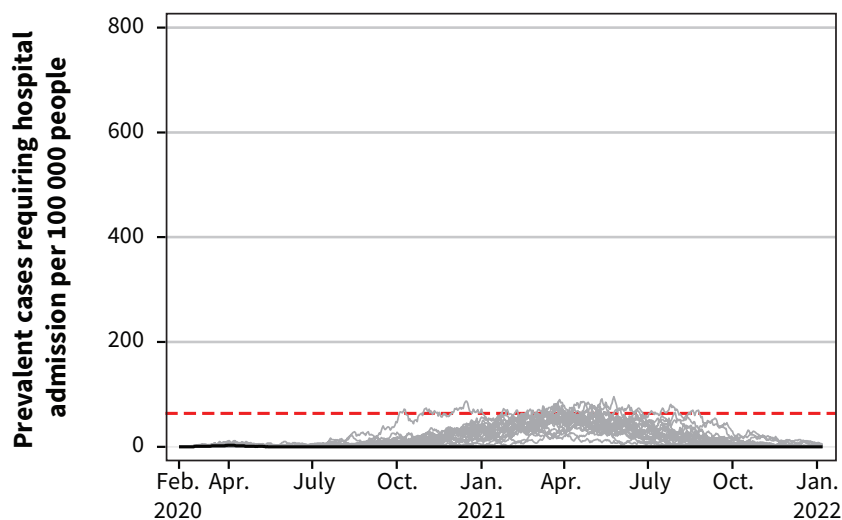

B

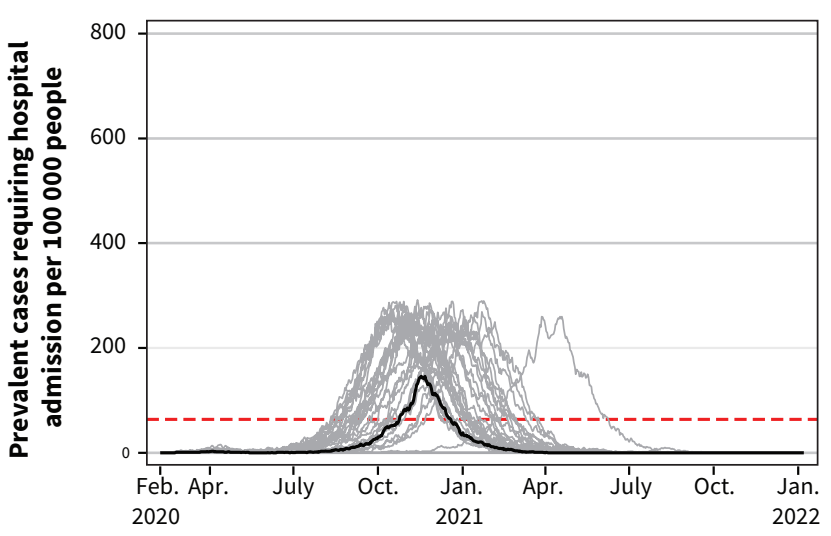

D

Combined interventions

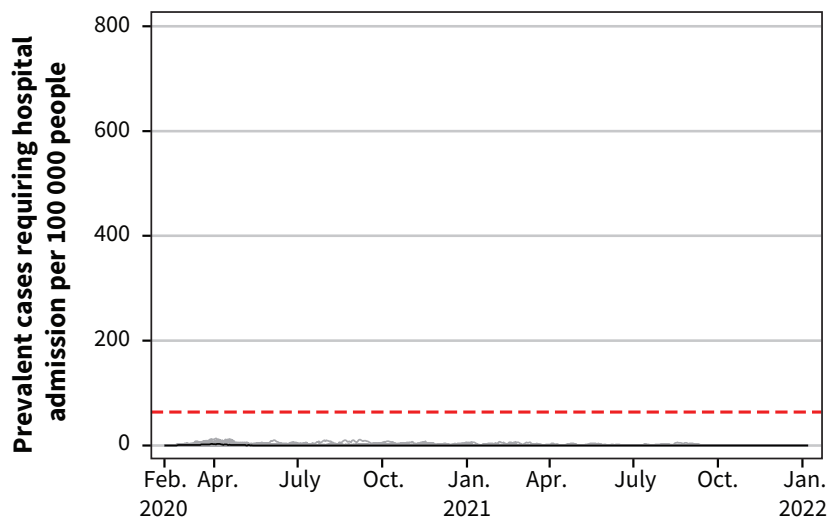

Figure 3: Projected hospital bed use showing daily hospital admission prevalence per 100000 people for the 4 scenarios. Note: Prevalent cases include those requiring general hospital admission in addition to those requiring pre-intensive care unit (ICU) and post-ICU hospital admission resulting from coronavirus disease 2019. The maximum Canadian hospital capacity is represented by the dashed horizontal red lines. Median values are represented by the black line. Each grey line represents 1 model realization out of 50 per scenario. 
extended school closure reduced the number of infections acquired in schools by 935 per 100000 under minimal control and 310 per 100000 under maintained physical distancing, compared with these scenarios without school closures, the overall impact of school closure on the epidemic is minor owing to continued community transmission. School closures resulted in higher transmission at home (379 and 287 additional infections per 100000 , respectively), which compensated partly for reduced transmission in schools. Under the enhanced case detection and contact tracing scenario or the combined interventions scenario, extended school closures controlled the epidemic in most realizations (Figure 5).

In comparison, extended closures of workplace and mixed-age venues tended to result in much lower total attack rates under minimal control $(0.4 \%, 95 \% \mathrm{Crl} 0.1 \%-$ $57.0 \%)$ and maintained physical distancing $(0.3 \%, 95 \% \mathrm{Crl}$ $0.04 \%-43.3 \%$ ) (Table 5). More than half of the realizations for workplace and mixed-age venue closures under these scenarios eliminated the epidemic, while under enhanced case detection and contact tracing or combined interventions, the epidemic was eliminated in all realizations (Figure 6). The greater effectiveness of partial closures of workplaces and mixed-age venues compared with full school closures was due to a higher proportion of infections being acquired in the workplace $(12.4 \%-14.4 \%)$ and mixed-age venues $(22.5 \%-25.6 \%)$ than in schools $(3.3 \%-9.0 \%)$ under either type of community closure across scenarios, given that there are many more individuals in the workforce and the community than in school and that community transmission and household transmission continue to occur during extended school closures.

The sensitivity analysis indicated that the model results were dependent on the transmission parameter $(\beta)$ and its associated reproduction number $\left(R_{0}\right)$. When $R_{0}$ was lowered to 2.4 (from the baseline estimate of $R_{0}=2.7$ ), both the enhanced case detection and contact tracing scenario and the combined interventions scenario eliminated the epidemic and kept hospital and ICU bed use within capacity in all realizations. When $\mathrm{R}_{0}$
A

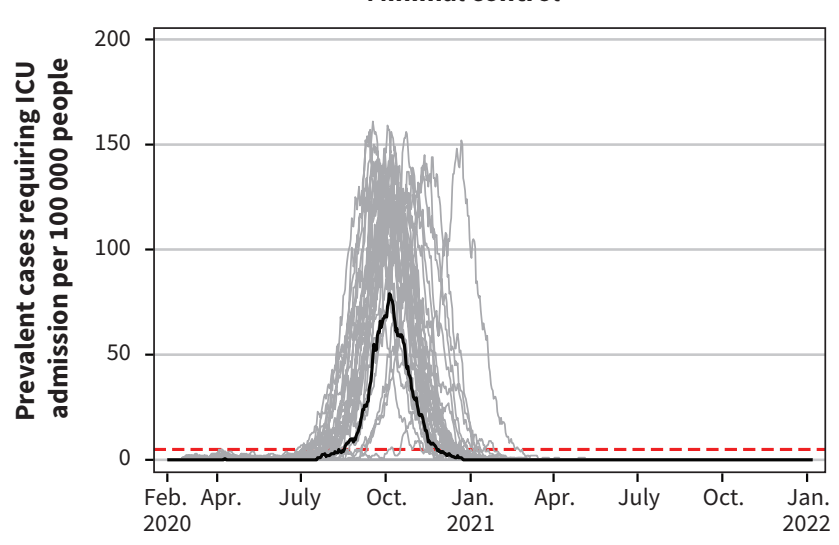

C Enhanced case detection and contact tracing

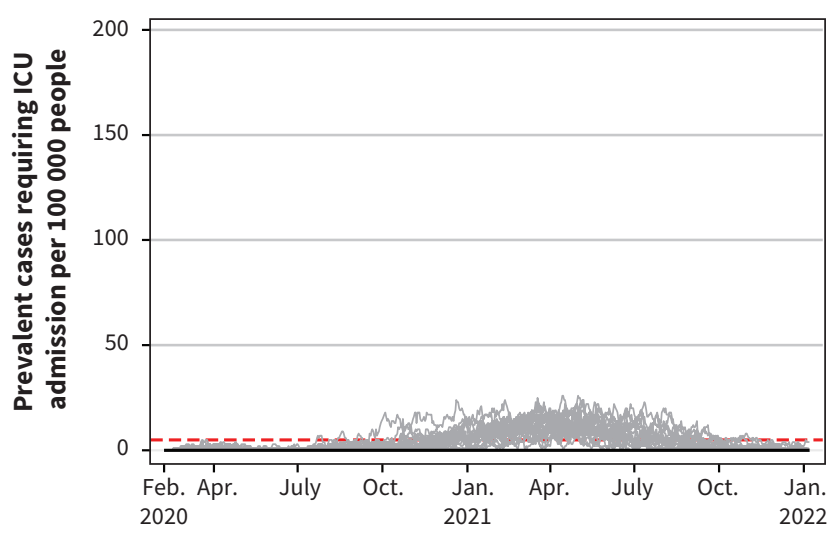

B

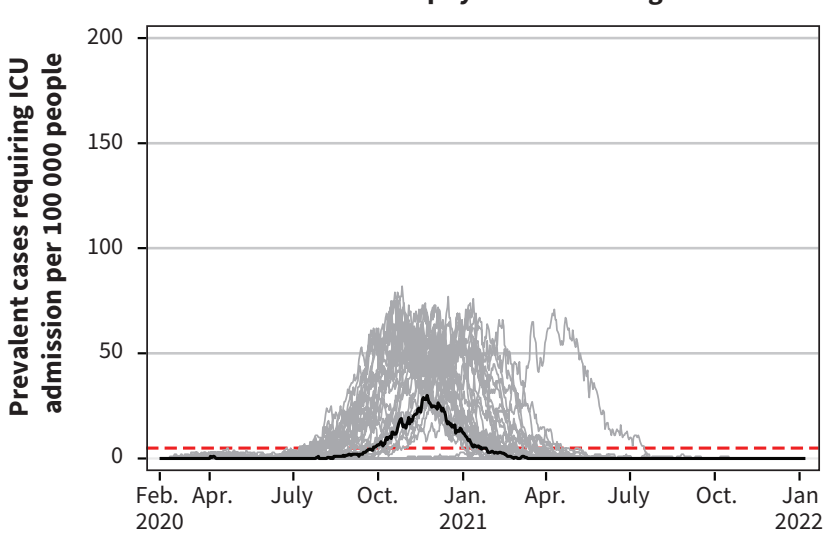

D

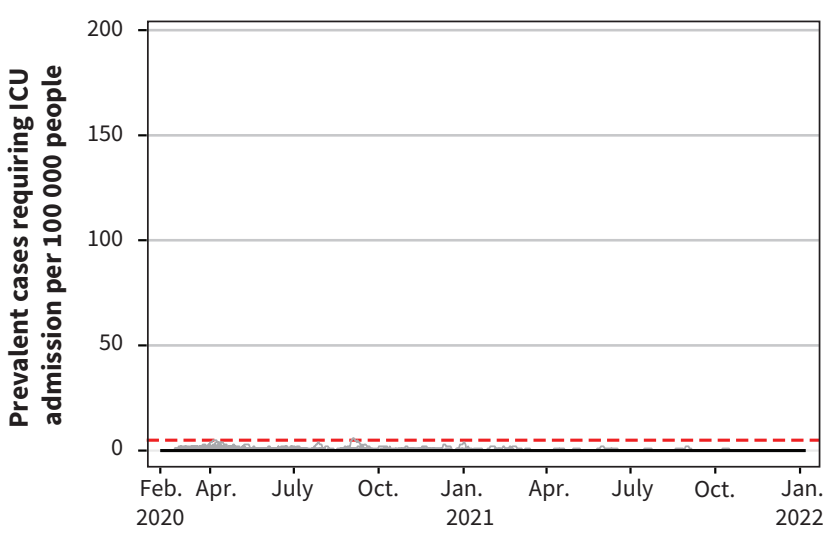

Figure 4: Projected intensive care unit (ICU) bed use showing daily ICU prevalence per 100000 people for the 4 scenarios. Note: The maximum Canadian ICU bed capacity is represented by the dashed horizontal red lines. Median values are represented by the black line. Each grey line represents 1 model realization out of 50 per scenario. 
was lowered further to 2.0, hospital and ICU bed use also remained below capacity under the maintained physical distancing scenario and even in most realizations under the minimal control scenario. In contrast, when $R_{0}$ was increased to 3.0, none of the scenarios controlled the epidemic and only the combined interventions scenario kept hospital and ICU bed use within capacity (Appendix 1, Figures S13-S24).

\section{Interpretation}

Our objective was to estimate the national situation of SARSCoV-2 transmission and model the challenges we are likely to face as we begin to lift restrictive closures in Canada that have been effective, but also have negative economic, social and health effects on society. The timing of easing of restrictive closures will largely depend on the regional situation in

Table 4: Summary of model outputs for the 4 scenarios studied with extended school closures*

\begin{tabular}{|c|c|c|c|c|}
\hline Variable & Minimal control & $\begin{array}{l}\text { Maintained } \\
\text { physical } \\
\text { distancing }\end{array}$ & $\begin{array}{l}\text { Enhanced case } \\
\text { detection and } \\
\text { contact tracing }\end{array}$ & $\begin{array}{c}\text { Combined } \\
\text { interventions }\end{array}$ \\
\hline Total attack rate, $\%(95 \% \mathrm{Crl})$ & $54.7(0.02-57.2)$ & $41.0(0.04-42.6)$ & $0.3(0.05-22.5)$ & $0.3(0.03-1.0)$ \\
\hline Clinical attack rate, $\%(95 \% \mathrm{Crl})$ & $33.5(0.02-35.1)$ & $25.1(0.02-26.2)$ & $0.2(0.04-13.7)$ & $0.19(0.0-0.6)$ \\
\hline Asymptomatic attack rate, $\%(95 \% \mathrm{Crl})$ & $21.1(0.0-22.1)$ & $15.8(0.01-16.7)$ & $0.1(0.02-8.8)$ & $0.11(0.01-0.4)$ \\
\hline $\begin{array}{l}\text { Proportion of asymptomatic cases of total cases, } \\
\%(95 \% \mathrm{Crl})\end{array}$ & $38.5(16.7-42.6)$ & $38.7(31.5-43.9)$ & $38.1(28.6-43.5)$ & $37.3(25.0-44.5)$ \\
\hline $\begin{array}{l}\text { Clinical cases that are mild (not admitted to hospital), } \\
\%(95 \% \mathrm{Crl})\end{array}$ & $89.0(78.0-93.2)$ & $89.5(80.0-91.4)$ & $89.8(81.2-94.2)$ & $89.9(81.2-94.7)$ \\
\hline $\begin{array}{l}\text { Clinical cases admitted to hospital (includes ICU), } \\
\%(95 \% \mathrm{Crl})\end{array}$ & $11.0(6.8-22.0)$ & $10.5(8.6-20.0)$ & $10.2(5.8-18.8)$ & $10.1(5.3-18.8)$ \\
\hline Clinical cases admitted into the ICU, \% (95\% Crl) & $2.8(0.0-6.2)$ & $2.7(0.0-8.7)$ & $2.8(0.9-12.5)$ & $2.4(0.0-6.9)$ \\
\hline $\begin{array}{l}\text { Hospital-admitted cases admitted into the ICU, } \\
\%(95 \% \mathrm{Crl})\end{array}$ & $25.6(0.0-50.0)$ & $25.5(0.0-66.7)$ & $29.3(9.1-66.7)$ & $22.5(0.0-50.0)$ \\
\hline Mortality rate of clinical cases, $\%(95 \% \mathrm{Crl})$ & $3.2(0.0-4.0)$ & $2.9(0.0-4.0)$ & $1.6(0.0-5.3)$ & $1.4(0.0-4.0)$ \\
\hline $\begin{array}{l}\text { Total cases (clinical and asymptomatic) per } 100000 \text {, } \\
\text { median ( } 95 \% \mathrm{Crl})\end{array}$ & $54668(24-57177)$ & $41003(35-42579)$ & $313(56-22533)$ & $297(28-990)$ \\
\hline Total clinical cases per 100000 , median $(95 \% \mathrm{Crl})$ & 33539 (20-35 083) & $25062(23-26158)$ & $198(37-13722)$ & $191(18-625)$ \\
\hline $\begin{array}{l}\text { Total asymptomatic cases per } 100000 \text {, median } \\
(95 \% \mathrm{Crl})\end{array}$ & $21082(4-22064)$ & $15955(12-16661)$ & $118(22-8811)$ & $110(8-365)$ \\
\hline $\begin{array}{l}\text { Total hospital-admitted cases per } 100000 \text {, median } \\
(95 \% \mathrm{Crl})\end{array}$ & $3652(5-3979)$ & $2490(3-2835)$ & $21(4-1409)$ & $19(2-67)$ \\
\hline $\begin{array}{l}\text { Total cases admitted into the ICU per } 100000 \text {, median } \\
(95 \% \mathrm{Crl})\end{array}$ & $930(0-996)$ & $658(0-727)$ & $6(1-348)$ & $4(0-17)$ \\
\hline Total deaths per 100000 , median $(95 \% \mathrm{Crl})$ & $1088(0-1203)$ & $712(0-790)$ & $3(0-252)$ & $3(0-12)$ \\
\hline Infections acquired at school, \% (95\% Crl) & $8.0(0.0-9.2)$ & $8.5(0.0-9.4)$ & $4.4(1.2-10.0)$ & $3.3(0.0-12.3)$ \\
\hline infections acquired at work, \% (95\% Crl) & $14.4(5.6-15.6)$ & $13.6(5.6-20.6)$ & $13.4(5.5-20.0)$ & $13.9(0.0-20.6)$ \\
\hline Infections acquired in mixed-age venues, \% (95\% Crl) & $25.6(16.8-32.8)$ & $24.2(19.4-31.0)$ & $23.3(14.7-32.1)$ & $23.6(15.4-31.8)$ \\
\hline Infections acquired in the household, \% (95\% Crl) & $51.8(51.0-64.0)$ & $53.5(52.9-72.2)$ & $59.7(51.1-64.5)$ & $58.9(51.5-68.2)$ \\
\hline $\begin{array}{l}\text { No. of infections acquired at school per } 100000 \text {, } \\
\text { median }(95 \% \mathrm{Crl})\end{array}$ & $4199(0-5169)$ & $3449(0-3874)$ & $12(2-2114)$ & $10(0-40)$ \\
\hline $\begin{array}{l}\text { No. of infections acquired at work per } 100000 \text {, } \\
\text { median }(95 \% \mathrm{Crl})\end{array}$ & $7943(1-8340)$ & $5611(2-5930)$ & $43(6-3008)$ & $44(0-124)$ \\
\hline $\begin{array}{l}\text { No. of infections acquired in mixed-age venue per } \\
100000 \text {, median ( } 95 \% \mathrm{Crl})\end{array}$ & $14190(7-14618)$ & $9924(7-10450)$ & $63(10-5286)$ & $68(5-254)$ \\
\hline $\begin{array}{l}\text { No. of infections acquired at home per } 100000 \text {, } \\
\text { median }(95 \% \mathrm{Crl})\end{array}$ & $28280(10-29259)$ & $21889(17-22795)$ & $186(32-12074)$ & $167(15-580)$ \\
\hline
\end{tabular}


provinces and territories. ${ }^{13,26}$ Our agent-based model found that all interventions studied were effective at reducing transmission to some degree, but enhancing case detection and isolation to capture $50 \%$ of all cases, while enhancing contact tracing to capture and quarantine all contacts of these cases, was most effective, especially when combined with maintaining physical distancing to reduce the contact rate among individuals in the population by $20 \%$. These interventions would need to be maintained until the epidemic is extinguished (either via herd immunity or vaccination), or there will be a resurgence.

Partial community closure was the only intervention explored that was capable of driving the epidemic to extinction on its own. Our results suggest this would be driven primarily by workplace and mixed-age venue closures rather than school closures. School closures, while useful to prevent transmission in schools, added little to the effects of partial community closures and were not effective on their own to reduce the overall attack rate and control the epidemic, particularly if community transmission driven by individuals who are asymptomatic or presymptomatic but infectious - persists. Without additional public health measures, school closures will only delay an epidemic. ${ }^{14}$ Our findings are consistent with early studies that suggest closing schools may not be as effective as other less restrictive measures. ${ }^{27}$ Workplace and general community closures were shown to be much more effective, because transmission is occurring predominantly in these settings.

Consistent with international studies, ${ }^{14,28}$ we found that without any intervention, about two-thirds of Canadians will become infected. Realistic interventions consistent with current efforts being made in Canada were projected to reduce the proportion of the population infected only slightly or almost entirely, depending on the trajectory of our efforts in the coming months, consistent with other models. ${ }^{14,16}$ The actual attack rate we will see will depend on the degree to which case detection and isolation and contact tracing and quarantine are ramped up,,$^{21,29}$ and
A

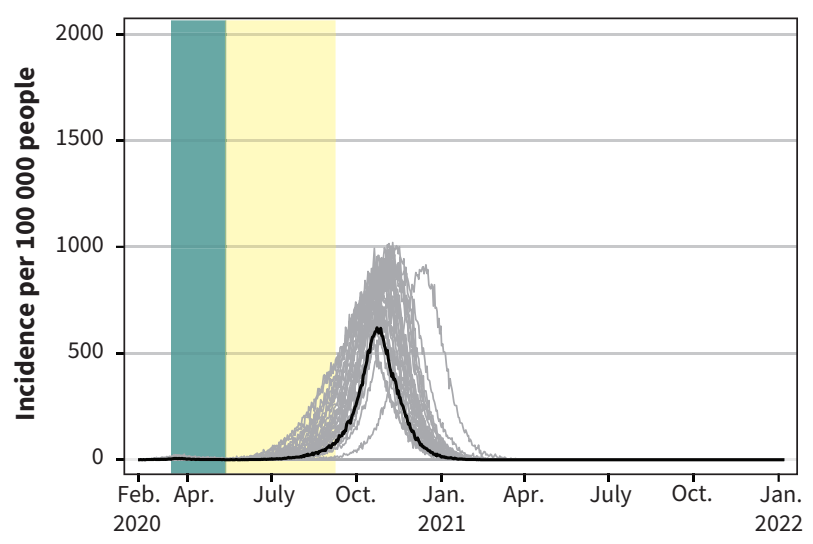

C Enhanced case detection and contact tracing

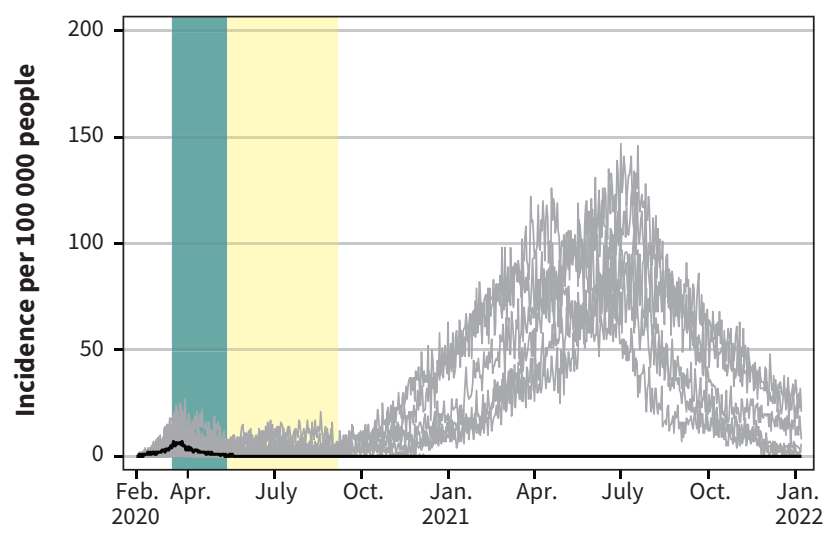

B Maintained physical distancing

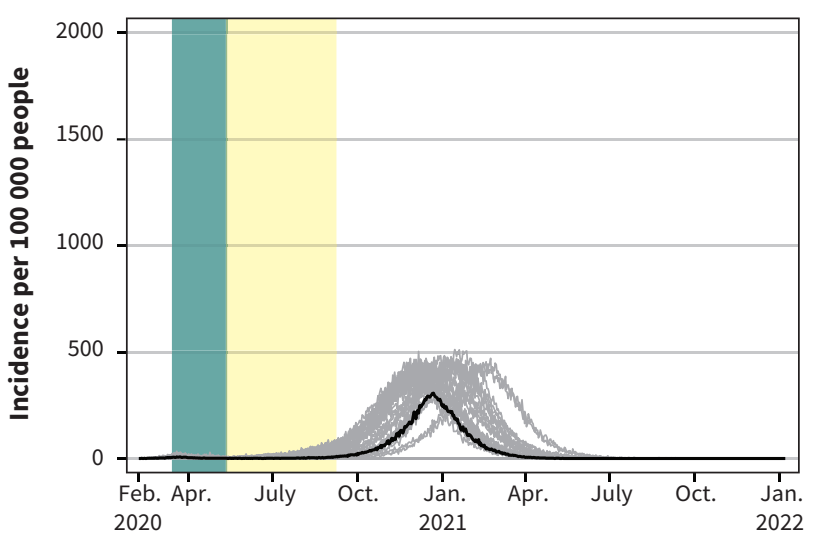

D Combined interventions

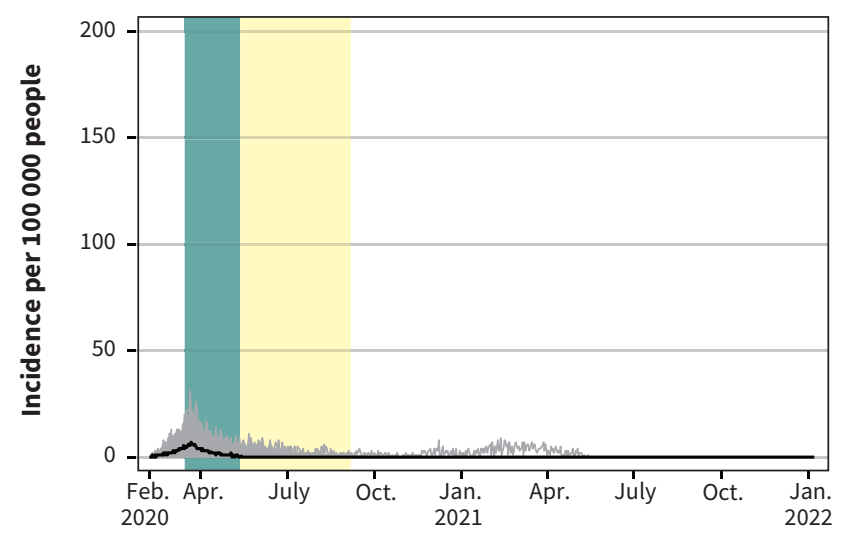

Figure 5: Projected epidemic curves showing daily case incidence per 100000 people for for the 4 scenarios with extended school closures. Note: Each scenario progressively applies increasing public health measures. The green bar represents the period from Mar. 16 to May 10, 2020, corresponding to restrictive closures. The yellow bar represents the period from May 11 to Sept. 8, 2020, corresponding to school closures only. Median values are represented by the black line. Each grey line represents 1 model realization out of 50 per scenario. The $y$-axis scale for the enhanced case detection and contact tracing scenario and the combined interventions scenario is 10 times smaller. 
the degree to which the Canadian public adheres to personal physical distancing and other personal protective measures. ${ }^{22,24,30}$ If we release restrictive closures without ramping up other public health measures, the epidemic will resurge with a magnitude depending on our future effort, and could exceed the capacity of our health care system and require the reimplementation of lockdown restrictions.

\section{Limitations}

Many key epidemiologic characteristics of SARS-CoV-2 remain unknown, particularly whether children are less susceptible to infection than adults, the true proportion of asymptomatic infections and whether recovery from COVID-19 confers lasting immunity to SARS-CoV-2. We developed a national model that attempts to aggregate heterogenous regional epidemics; as

Table 5: Summary of model outputs for the 4 scenarios studied with extended community (workplace and mixed-age venue) closures*

\begin{tabular}{|c|c|c|c|c|}
\hline Variable & Minimal control & $\begin{array}{l}\text { Maintained } \\
\text { physical } \\
\text { distancing }\end{array}$ & $\begin{array}{l}\text { Enhanced case } \\
\text { detection and } \\
\text { contact tracing }\end{array}$ & $\begin{array}{l}\text { Combined } \\
\text { interventions }\end{array}$ \\
\hline Total attack rate, $\%(95 \% \mathrm{Crl})$ & $0.4(0.1-57.0)$ & $0.3(0.04-43.3)$ & $0.2(0.03-0.9)$ & $0.2(0.07-0.9)$ \\
\hline Clinical attack rate, $\%(95 \% \mathrm{Crl})$ & $0.3(0.06-34.9)$ & $0.2(0.03-26.5)$ & $0.1(0.02-0.6)$ & $0.2(0.05-0.5)$ \\
\hline Asymptomatic attack rate, $\%(95 \% \mathrm{Crl})$ & $0.2(0.03-22.2)$ & $0.1(0.01-16.8)$ & $0.1(0.01-0.3)$ & $0.1(0.02-0.3)$ \\
\hline $\begin{array}{l}\text { Proportion of asymptomatic cases of total cases, } \\
\%(95 \% \mathrm{Crl})\end{array}$ & $38.5(33.8-42.6)$ & $38.8(28.0-43.6)$ & $37.9(25.3-44.7)$ & $37.5(27.4-44.3)$ \\
\hline $\begin{array}{l}\text { Clinical cases that are mild (not admitted to hospital), } \\
\%(95 \% \mathrm{Crl})\end{array}$ & $89.0(85.5-93.1)$ & $89.6(83.3-93.8)$ & $89.5(82.2-93.2)$ & $89.6(79.7-93.1)$ \\
\hline $\begin{array}{l}\text { Clinical cases admitted to hospital (includes ICU), } \\
\%(95 \% \mathrm{Crl})\end{array}$ & $11.0(6.9-14.5)$ & $10.4(6.2-16.7)$ & $10.5(6.8-17.8)$ & $10.4(6.9-20.3)$ \\
\hline Clinical cases admitted into the ICU, \% (95\% Crl) & $2.8(0.7-5.2)$ & $2.6(0.0-42.9)$ & $2.7(0.0-7.4)$ & $2.8(0.4-6.1)$ \\
\hline $\begin{array}{l}\text { Hospital-admitted cases admitted into the ICU, } \\
\%(95 \% \mathrm{Crl})\end{array}$ & $25.6(5.3-57.1)$ & $24.7(0.0-42.9)$ & $25.9(0.0-55.6)$ & $23.8(4.0-46.7)$ \\
\hline Mortality rate of clinical cases, $\%(95 \% \mathrm{Crl})$ & $3.2(0.0-4.7)$ & $1.7(0.0-4.8)$ & $1.4(0.0-4.3)$ & $1.5(0.0-5.1)$ \\
\hline $\begin{array}{l}\text { Total cases (clinical and asymptomatic) per } 100000 \text {, } \\
\text { median ( } 95 \% \mathrm{Crl})\end{array}$ & $436(96-56988)$ & $290(42-43333)$ & $237(30-886)$ & $226(70-869)$ \\
\hline Total clinical cases per 100000 , median $(95 \% \mathrm{Crl})$ & $263(58-34923)$ & $169(29-26531)$ & $143(22-549)$ & $145(46-543)$ \\
\hline $\begin{array}{l}\text { Total asymptomatic cases per } 100000 \text {, median } \\
(95 \% \mathrm{Crl})\end{array}$ & $166(34-22192)$ & $119(13-16802)$ & $89(7-337)$ & $91(22-326)$ \\
\hline $\begin{array}{l}\text { Total hospital-admitted cases per } 100000 \text {, } \\
\text { median }(95 \% \mathrm{Crl})\end{array}$ & $27(4-3922)$ & $18(5-2758)$ & $16(2-54)$ & $15(5-60)$ \\
\hline $\begin{array}{l}\text { Total cases admitted into the ICU per } 100000 \text {, } \\
\text { median }(95 \% \mathrm{Crl})\end{array}$ & $11(1-1019)$ & $5(0-705)$ & $5(0-15)$ & $4(1-16)$ \\
\hline Total deaths per 100000 , median $(95 \% \mathrm{Crl})$ & $5(0-1218)$ & $3(0-784)$ & $2(0-12)$ & $2(0-9)$ \\
\hline Infections acquired at school, \% (95\% Crl) & $9.0(1.0-11.6)$ & $4.2(0.0-9.4)$ & $4.0(0.0-8.2)$ & $4.0(0.0-8.7)$ \\
\hline infections acquired at work, \% (95\% Crl) & $14.2(3.8-20.5)$ & $13.6(8.3-18.4)$ & $12.4(5.3-18.9)$ & $12.5(7.1-23.0)$ \\
\hline Infections acquired in mixed-age venues, \% (95\% Crl) & $25.3(13.1-33.9)$ & $22.8(16.3-28.4)$ & $22.5(12.2-29.1)$ & $22.5(16.2-30.5)$ \\
\hline Infections acquired in the household, \% (95\% Crl) & $54.7(50.9-62.7)$ & $59.6(53.0-67.1)$ & $60.2(56.7-75.0)$ & $59.8(52.2-64.1)$ \\
\hline $\begin{array}{l}\text { No. of infections acquired at school per } 100000 \text {, } \\
\text { median }(95 \% \mathrm{Crl})\end{array}$ & $29(1-5307)$ & $11(0-3900)$ & $9(0-53)$ & $10(0-60)$ \\
\hline $\begin{array}{l}\text { No. of infections acquired at work per } 100000 \text {, } \\
\text { median }(95 \% \mathrm{Crl})\end{array}$ & $62(5-8194)$ & $41.5(5-5948)$ & $30(1-105)$ & $31(6-125)$ \\
\hline $\begin{array}{l}\text { No. of infections acquired in mixed-age venue per } \\
100000 \text {, median }(95 \% \mathrm{Crl})\end{array}$ & $109(17-14513)$ & $60(8-10461)$ & $52(4-201)$ & 47 (14-199) \\
\hline $\begin{array}{l}\text { No. of infections acquired at home per } 100000 \text {, } \\
\text { median ( } 95 \% \mathrm{Crl})\end{array}$ & $243(52-29116)$ & $173(22-22991)$ & $138(15-541)$ & $139(35-508)$ \\
\hline
\end{tabular}


A

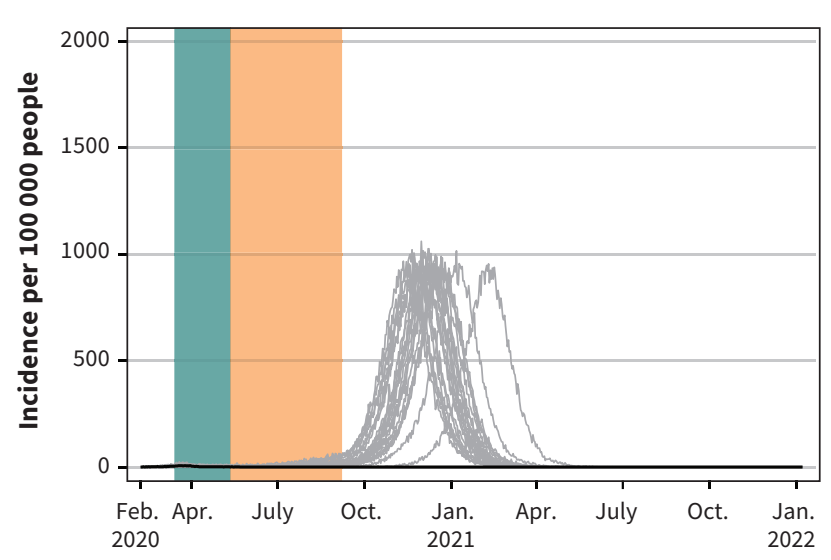

C Enhanced case detection and contact tracing

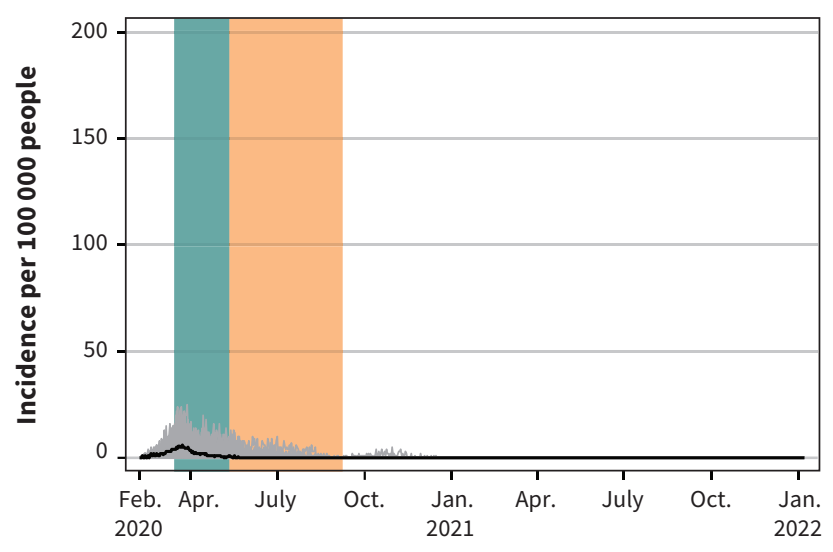

B

D

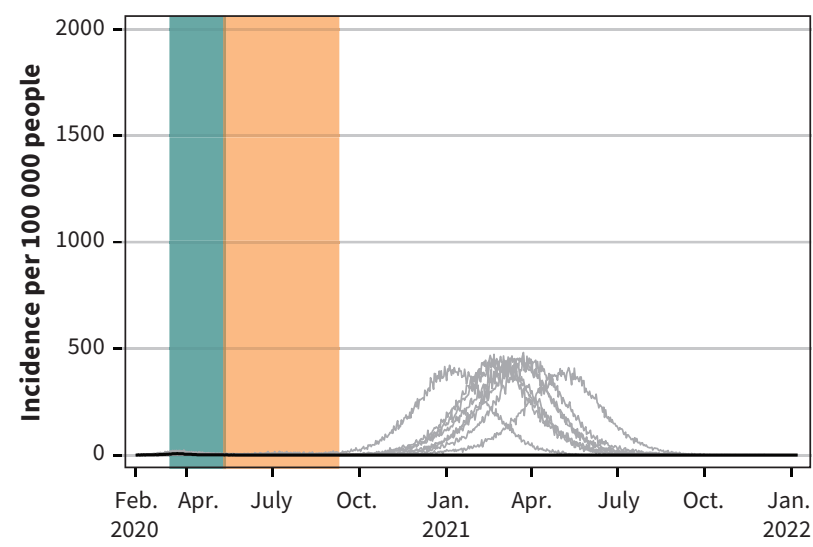

D Combined interventions

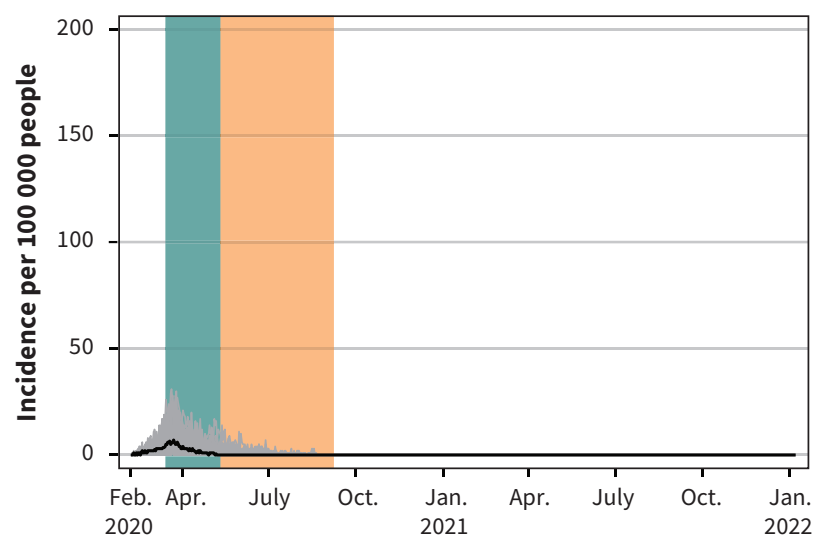

Figure 6: Projected epidemic curves showing daily case incidence per 100000 people for the 4 scenarios with extended school closures. Note: Each scenario progressively applies increasing public health measures. The green bar represents the period from Mar. 16 to May 10, 2020, corresponding to restrictive closures. The orange bar represents the period from May 11 to Sept. 8, 2020, corresponding to extended workplace and mixed-age venue closures only. Median values are represented by the black line. Each grey line represents 1 model realization out of 50 per scenario. The $y$-axis scale for the enhanced case detection and contact tracing scenario and the combined interventions scenario is 10 times smaller.

such, our model may not accurately describe SARS-CoV-2 transmission across all communities in Canada. However, Canadian data were used to calibrate the model, and results show good fit to locally acquired cases. Our model does not account for transmission among health care workers and residents of longterm care facilities, which are the source of multiple outbreaks across Canada. As transmission in health care workers and long-term care facilities are occurring at varying magnitude across provinces and territories, a national model is not suitable to address these regional and localized clusters. Further, the settings in which these localized outbreaks are occurring face unique challenges often requiring more intensive infection prevention and control interventions that are not implemented at the population level. ${ }^{31}$ This model is representative of the general Canadian situation and provides a baseline projection of community transmission in Canada. Our results will therefore need to be interpreted recognizing that in some circumstances localized outbreaks may result in higher numbers of cases, hospital admissions and deaths than projected.

\section{Conclusion}

The model provides early estimates of COVID-19 transmission in the Canadian population and the impact of combining interventions to reduce and eliminate transmission in Canada. Early efforts to control the epidemic in Canada were largely successful, but as restrictive measures across the country are lifted, enhancement of other control measures is needed to prevent transmission, minimize cases, and ensure Canada's health systems are not overwhelmed.

\section{References}

1. WHO Director-General's remarks at the media briefing on COVID-19-11 March 2020 [speech]. Geneva: World Health Organization; 2020. Available: www.who.int/dg/speeches/detail/who-director-general-s-opening-remarks-at -the-media-briefing-on-covid-19---11-march-2020 (accessed 2020 May 2).

2. Coronavirus disease 2019 (COVID-19): situation report, 51. Geneva: World Health Organization; 2020:1-9.

3. COVID-19 Dashboard by the Center for Systems Science and Engineering (CSSE) at Johns Hopkins University. Baltimore: Johns Hopkins University. Available: https://gisanddata.maps.arcgis.com/apps/opsdashboard/index. html\#/bda7594740fd40299423467b48e9ecf6 (accessed 2020 June 28). 
4. Wu Z, McGoogan JM. Characteristics of and important lessons from the coronavirus disease 2019 (COVID-19) outbreak in China: summary of a report of 72314 cases from the Chinese Center for Disease Control and Prevention. JAMA 2020;323:1239-42. doi: 10.1001/jama.2020.2648.

5. Garg S, Kim L, Whitaker M, et al. Hospitalization rates and characteristics of patients hospitalized with laboratory-confirmed coronavirus disease 2019 COVID-NET, 14 states, March 1-30, 2020. MMWR Morb Mortal Wkly Rep 2020;69:458-64.

6. Wang D, Hu B, Hu C, et al. Clinical characteristics of 138 hospitalized patients with 2019 novel coronavirus-infected pneumonia in Wuhan, China. JAMA 2020;323:1061-9.

7. Hu Z, Song C, Xu C, et al. Clinical characteristics of 24 asymptomatic infections with COVID-19 screened among close contacts in Nanjing, China. Sci China Life Sci 2020;63:706-11.

8. Xia W, Liao J, Li C, et al. Transmission of corona virus disease 2019 during the incubation period may lead to a quarantine loophole. medRxiv 2020 Mar. 8. doi: 10.1101/2020.03.06.20031955.

9. Tong Z-D, Tang A, Li K-F, et al. Potential presymptomatic transmission of SARS-CoV-2, Zhejiang Province, China, 2020. Emerg Infect Dis 2020;26:1052-4.

10. Wei WE, Li Z, Chiew CJ, et al. Presymptomatic transmission of SARS-CoV-2 Singapore, January 23-March 16, 2020. MMWR Morb Mortal Wkly Rep 2020;69:411-5.

11. Silverstein WK, Stroud L, Cleghorn GE, et al. First imported case of 2019 novel coronavirus in Canada, presenting as mild pneumonia. Lancet 2020;395:734.

12. Coronavirus disease 2019 (COVID-19): daily epidemiological update. Ottawa: Public Health Agency of Canada; modified 2020 July 20. Available: https://health -infobase.canada.ca/covid-19/epidemiological-summary-covid-19-cases.html (accessed 2020 June 10).

13. Federal/provincial/territorial COVID-19 interventions [internal document]. Ottawa: Health Canada; 2020 May 4. Available from the author on request.

14. Ferguson N, Laydon D, Nedjati-Gilani G, et al. Report 9: Impact of non-pharmaceutical interventions (NPIs) to reduce COVID-19 mortality and healthcare demand. London (UK): Imperial College London; 2020.

15. Hellewell J, Abbott S, Gimma A, et al. Feasibility of controlling COVID-19 outbreaks by isolation of cases and contacts. Lancet Glob Health 2020;8:e488-96.

16. Tuite AR, Fisman DN, Greer AL. Mathematical modelling of COVID-19 transmission and mitigation strategies in the population of Ontario, Canada. CMAJ 2020;192:E497-505

17. Kermack W, McKendrick A. A contribution to the mathematical theory of epidemics. Proc R Soc Lond, A Contain Pap Math Phys Character 1927;115:700-21. doi: 10.1098/ rspa.1927.0118.

18. Althaus CL. Estimating the reproduction number of Ebola virus (EBOV) during the 2014 outbreak in West Africa. PLoS Curr 2014;6:ecurrents.outbreaks.91afb5 e0f279e7f29e7056095255b288. doi: 10.1371/currents.outbreaks.91afb5e0f279e $7 f 29 e 7056095255 b 288$.
19. Chao DL, Oron AP, Srikrishna D, et al. Modeling layered non-pharmaceutical interventions against SARS-CoV-2 in the United States with Corvid. medRxiv 2020 Apr. 11. doi: 10.1101/2020.04.08.20058487.

20. Davies NG, Kucharski AJ, Eggo RM, et al. Centre for the Mathematical Modelling of Infectious Diseases COVID-19 working group. Effects of non-pharmaceutical interventions on COVID-19 cases, deaths, and demand for hospital services in the UK: a modelling study. Lancet Public Health 2020;5:e375-85.

21. Using a delay-adjusted case fatality ratio to estimate under-reporting. London (UK): Centre for Mathematical Modeling of Infectious Diseases, London Schoo of Hygiene \& Tropical Medicine; 2020 Mar. 22, updated 2020 June 21. Available: https://cmmid.github.io/topics/covid19/global_cfr_estimates.html (accessed 2020 June 21)

22. COVID-19 Community Mobility Report. Google Canada; 2020. Available: www. gstatic.com/covid19/mobility/2020-05-09_CA_Mobility_Report_en.pdf (accessed 2020 May 9).

23. Canadian Perspectives Survey Series 1: COVID-19 and working from home 2020. The Daily. Ottawa: Statistics Canada; 2020. Available: www150.statcan gc.ca/n1/daily-quotidien/200417/dq200417a-eng.pdf (accessed 2020 Apr. 17).

24. How are Canadians coping with the COVID-19 situation? [infographic]. Ottawa: Statistics Canada; modified 2020 Apr. 20. Available: www150.statcan.gc.ca/n1/ pub/11-627-m/11-627-m2020029-eng.htm (accessed 2020 Apr. 19).

25. Tang B, Scarabel F, Bragazzi NL, et al. De-escalation by reversing the escalation with a stronger synergistic package of contact tracing, quarantine, isolation and personal protection: feasibility of preventing a COVID-19 rebound in Ontario, Canada, as a case study. Biology (Basel) 2020;9:100.

26. Canada COVID-19 Situation Awareness Dashboard. Ottawa: Public Health Agency of Canada. Available: https://phac-aspc.maps.arcgis.com/apps/opsdashboard/ index.html\#/e968bf79f4694b5ab290205e05cfcda6 (accessed 2020 June 27).

27. Viner RM, Russell SJ, Croker $\mathrm{H}$, et al. School closure and management practices during coronavirus outbreaks including COVID-19: a rapid systematic review. Lancet Child Adolesc Health 2020;4:397-404.

28. Kwok KO, Lai F, Wei WI, et al. Herd immunity - estimating the level required to halt the COVID-19 epidemics in affected countries. J Infect 2020;80:e32-3.

29. Scarabel F, Pellis L, Bragazzi NL, et al. Canada needs to rapidly escalate public health interventions for its COVID-19 mitigation strategies. Infect Dis Model 2020;5:316-22. doi: 10.1016/j.idm.2020.03.004

30. Chu DK, Akl EA, Duda S, et al.; COVID-19 Systematic Urgent Review Group Effort (SURGE) study authors. Physical distancing, face masks, and eye protection to prevent person-to-person transmission of SARS-CoV-2 and COVID-19: a systematic review and meta-analysis. Lancet 2020;395:1973-87.

31. Callaghan AW, Chard AN, Arnold P, et al. Screening for SARS-CoV-2 infection within a psychiatric hospital and considerations for limiting transmission within residential psychiatric facilities - Wyoming, 2020. MMWR Morb Mortal Wkly Rep 2020;69:825-9.

\section{Competing interests: None declared.}

This article has been peer reviewed

Affiliations: Public Health Risk Sciences Division (Ng, Fazil, Waddell, Turgeon, Otten, Ogden), National Microbiology Laboratory, Infectious Disease Prevention and Control Branch, Public Health Agency of Canada, Guelph, Ont., and St. Hyacinthe, Que.; Centre for Immunization and Respiratory Infectious Diseases (Bancej), Infectious Disease Prevention and Control Branch, Public Health Agency of Canada, Ottawa, Ont.; Office of Biosecurity Programs and Planning (Atchessi), Centre for Biosecurity, Health Security Infrastructure Branch, Public Health Agency of Canada, Ottawa, Ont.
Contributors: Victoria Ng, Aamir Fazil and Nicholas Ogden contributed to the conceptualization. Ainsley Otten, Lisa Waddell and Nicole Atchessi contributed to the data collection. Victoria $\mathrm{Ng}$ contributed to the analysis. Christina Bancej and Patrician Turgeon contributed to the interpretation of the data. Victoria $\mathrm{Ng}$, Christina Bancej and Patricia Turgeon drafted the article, which all of the authors revised. All of the authors gave final approval of the version to be published and agreed to be accountable for all aspects of the work.

Data sharing: All the data from the model outputs can be made publicly available on request to the corresponding author. Epidemiologic data inputs can also be made publicly available on request to the corresponding author. Data on COVID-19 cases and hospital admission and mortality on COVID-19 cases will be subject to privacy law. Interested individuals can contact the corresponding author, and the corresponding author will put them in touch with the original data provider.

Acknowledgements: The authors thank Lujie Duan from the University of Saskatchewan, André Jacques from SimWell Consulting and Technologies and Deirdre Hennessy from Statistics Canada for their technical support.

Accepted: July 21, 2020

Correspondence to: Victoria Ng, victoria.ng@ canada.ca 